\title{
THE MEDIATING EFFECT OF WORK-LIFE BALANCE ON THE RELATIONSHIP BETWEEN WORK CULTURE AND EMPLOYEE WELL-BEING
}

\author{
Asta STANKEVIČIENĖ ${ }^{1}$, Virginijus TAMAŠEVIČIUS ${ }^{1^{*}}$, Danuta DISKIENE ${ }^{1}$, \\ Žygimantas GRAKAUSKAS ${ }^{1}$, Liana RUDINSKAJA ${ }^{2}$ \\ ${ }^{1}$ Department of Management Faculty of Economics and Business Administration, \\ Vilnius University, Vilnius, Lithuania \\ ${ }^{2}$ Vilnius University, Vilnius, Lithuania
}

Received 18 August 2020; accepted 24 February 2021

\begin{abstract}
This article tends to fill the existing knowledge gap in understanding if work-life balance (WLB) can not only make a direct impact on employee well-being, but also play a mediating role between work culture and well-being. The purpose of this study was to investigate the mediating effect of WLB on the relationship between the structural dimensions of work culture - temporal flexibility, supportive supervision and operational flexibility - and employee well-being. The data were collected on the basis of a survey of employees employed by business and public sector organisations in Lithuania. The research revealed that all the components of work culture were important factors in defining employee well-being, had a strong direct impact on well-being and affected WLB. The results demonstrated that a direct effect of work culture on well-being was much stronger than the one moderated by an indirect effect of WLB. The findings also suggest that family-friendly culture can help employees to reach a better WLB, which, in its turn, assists employees in feeling higher satisfaction with general well-being at work. The current study expands the role of WLB as a mediator in organisational settings and its findings may be important for practitioners who seek to improve the performance of their organisation by enhancing the well-being of employees.
\end{abstract}

Keywords: well-being, work culture, temporal flexibility, supportive supervision, operational flexibility, work-life balance, mediator analysis.

JEL Classification: I31, M12, M14, O15.

\section{Introduction}

The new reality of the world caused by Covid-19 pandemic has exposed distressed economies and acute political, economic and social issues all over the globe leading to new challenges for organisations to sustain their vitality and ensure survival, prompt responsiveness and adjustment in their performance and workforce management (George et al., 2016; Carnevale

${ }^{\star}$ Corresponding author. E-mail: virginijus.tamasevicius@evaf.vu.lt 
\& Hatak, 2020). Organisations have to strive to help their employees cope with and adjust to their newly altered work modes and private spheres (Chawla et al., 2020).

In spite of the fact that the concepts of well-being and WLB have gained much scholarly attention, the present studies in these spheres are becoming crucially relevant. Recent studies have increasingly emphasised the importance of employee well-being and WLB in the organisational environment (Mishra \& Kapoor, 2017; Goodman et al., 2018; Sheikh et al., 2018). Employee well-being is one of the key factors that not only defines a long-term effectiveness of organisations but is also one of the essential sources of employee productivity. Many researchers suggest that employee well-being is associated with higher professional success, higher income, higher loyalty and overall productivity (Robertson \& Cooper, 2010; McCarty et al., 2011).

Cooper (2008) argues that today a special attention is given to well-being as a business management strategy. Therefore, there is a fundamental change in the employers' perceptions of employee health and its impact on the overall financial welfare of a company. Organisational leaders realize that healthier employees are more efficient, and a real strategic advantage in any organisation is achieved by combining lower health care costs with higher employee productivity. However, to keep employees satisfied and productive, it is necessary to enhance their well-being at work and working conditions. As previous research shows, an important condition for experiencing well-being is considered to be the WLB felt by employees (Boxall \& Macky, 2014) as it influences their productivity (Mishra \& Kapoor, 2017). It has been revealed that organisations that take care of their employees can strengthen and stabilize the employee's work and personal life by investing in human resource management policies, appropriate WLB strategies and paying attention to factors that help employees achieve a beneficial symmetry between work and personal needs, which helps to ensure well-being (Ollier-Mallaterre \& Foucreault, 2017). In parallel with the growing importance of employee well-being and WLB, it is important to find out the links between these spheres and reveal the measures that are most effective to ensure the most valuable benefits not only for the individual but also for the organisation.

The evidence found in literature shows that different groups of factors help to ensure the well-being of employees (Viot \& Benraiss-Noailles, 2019; Zheng et al., 2015). The findings suggest that one of the most important factors is the organisational culture that is family friendly and distinguished by temporal flexibility, operational flexibility and supportive supervision (Clark, 2001). However, previous research on ensuring employee well-being through organisational culture tools (Beauregard, 2011; Nierenberg et al., 2017) revealed insufficient amount of studies carried out into the main means of well-being. Even though some researchers investigated different aspects of work culture and its relationship with employee well-being and WLB, there is a lack of studies (Hoeven \& Zoonen, 2015) concerning the mediating effect of WLB on the relationship between work culture and employee wellbeing.

Consequently, employee well-being and WLB still remain among the important issues to be solved in different organisations, especially taking in account the world economic and social changes caused by a pandemic-driven lockdown (He \& Harris, 2020). Therefore, the organisations that strive for the well-being of their employees need specific research that 
can answer such important questions: what are the links between ensuring the well-being of employees and WLB and what are the most effective key measures in ensuring well-being and WLB? Thus, the object of the current research was the relationship between employee wellbeing, work culture and work-life balance. The main aim of the study was to investigate the mediating effect of WLB on the relationship of work culture and employee well-being. Our research objectives were as follows: to conceptualize the links between work culture, worklife balance and well-being; to reveal if WLB mediates the relationship between work culture and employee well-being; to assess how WLB mediates the relationship between structural dimensions of work culture (temporal flexibility, operational flexibility, and supportive supervision) and employee well-being. The research methods deployed were the analysis and synthesis of scientific literature, a survey. The survey was conducted in companies in Lithuania.

The structure of the paper is as follows: theoretical framework, research methodology, research results, discussion and conclusions. The theoretical framework presents the literature review associated with the issue and outlines the hypotheses built on theoretical studies. The next section explains the design of the empirical research. The section on research results provides the results of the empirical study of the relationship of work culture with employee well-being and the effect of WLB as a mediator on it. Finally, the discussion, the main conclusions and the limitations of the study are presented.

The findings of the study make a significant contribution to the existing scientific literature on well-being since it has revealed whether work culture has a direct impact on employee well-being, or whether WLB mediates this relationship.

\section{Theoretical framework}

\subsection{The concept of well-being}

Despite the ongoing discussion in the scientific literature, there is no clear agreement among scholars concerning either the conceptualization of well-being or its indicators, or the factors that may serve as tools to better perceive it. Although scholars recognise well-being to be a multidimensional state, they have not yet come up with a unified viewpoint on the definition of well-being and continue discussions whether well-being can be viewed from a broad and narrow perspective or as a social (overall well-being) and individual phenomena (individual well-being) (Viot \& Benraiss-Noailles, 2019).

The concept of employee well-being is flexible and varies greatly between generations, regions, countries, social values and customs. Several terms are commonly used in the scientific literature, which mean in part the same but emphasize somewhat different features of well-being: psychological well-being (Ryff \& Keyes, 1995), subjective well-being (Diener et al., 1999), life well-being (Zheng et al., 2015), quality of life, subjective quality of life (Henrich \& Herschbach, 2000). The concept of well-being can be understood as the provision of material and spiritual goods (Qi \& Wu, 2018). Well-being is also a feeling or state when a person feels happy (Guest, 2017).

Managerial studies, in turn, mostly focus on physical, psychological and social well-being. Physical employee well-being reflects physiological indicators of health and illness in the workplace and is evaluated through the concept of subjective well-being. Typically, it is ex- 
amined through the subjective feelings of health, including positive indicators such as energy levels and negative indicators such as exhaustion and stress (Guest, 2017).

In terms of psychological well-being, two approaches can be stressed - eudemonic and hedonic. Both of them form the construct of employee well-being (Zheng et al., 2015). According to the eudemonic approach, psychological well-being is defined through meaningfulness and self-realization, and is characterized by the degree of realizing the personal potential power (Dodge et al., 2012; Zheng et al., 2015; Guest, 2017). Ryff and Keyes (1995) offered a eudemonic orientation as a background for a six-dimensional construct of the psychological well-being that involves self-acceptance, positive relations with others, autonomy, environment control, purpose in life and personal growth. According to the hedonic approach, psychological well-being (also referred by some authors as subjective well-being), is associated with happiness and defined through the pursuit of pleasurable experiences and the avoidance of pain. It is the satisfaction or happiness resultant from optimal functioning (Robertson \& Cooper, 2010; Guest, 2017; Viot \& Benraiss-Noailles, 2019). Diener et al. (1999) presented subjective well-being as a three-component construct covering the emotional experience of positive and negative emotions and the assessment of life satisfaction based on one's own personal standards. Negative emotions are usually associated with avoiding punishment (negative effects) and positive ones with reward (positive effects). The present study focused specifically on psychological well-being stressing the interactions between the individual and the organization and both positive and negative aspects of well-being at work.

Social well-being is examined by subjectively assessing interpersonal relationships, levels of social support, and the perceived trust and fairness in treatment (Guest, 2017). The indicators such as a person's feelings about the community in which he or she lives, including a sense of trust in other people; experiencing a sense of neighbourship; having a supportive relationship in private life, etc., are commonly researched by studying social well-being.

Generally speaking, all the mentioned dimensions of well-being are interrelated and examined by researchers, both in combination and separately. Studies have shown a group of factors that help to ensure the well-being of employees at the organisational level like benevolence to employees and insurance of working conditions (Viot \& Benraiss-Noailles, 2019), communication (Sakka \& Ahammad, 2020) at the personal level - e.g. personal abilities (Orsila et al., 2011), and at the context level - country culture (Zheng et al., 2015). Moreover, research has also shown a positive relationship between well-being and job satisfaction (Zheng et al., 2015), full engagement (Robertson \& Cooper, 2010), commitment (Meyer \& Maltin, 2010; Jain et al., 2013), productivity and sickness/absence levels (Robertson \& Cooper, 2010) while a negative relationship was observed with absenteeism and intention to leave the company (Viot \& Benraiss-Noailles, 2019), and emotional exhaustion and burnout (Parker et al., 2012).

\subsection{Work-life balance}

In spite of the fact that WLB has recently become an increasingly relevant research topic there is still a lack of commonly accepted definition among scholars. The early studies on work and private life applied the term work-family balance. Such studies mostly emphasized employees with childcare responsibilities, especially females. Later it was recognized that all 
employees had non-work - related private life. Therefore, researchers focused on the issues related to the distribution of time for work and social life. Grisslich et al. (2012) pointed out that individuals needed to devote time for themselves too, and Evans et al. (2013) found that by combining work and private life, engagement in family well-being and childcare became relevant for men as well.

As a result, the concept of work and private life started to be used. Part of the researchers conceptualize WLB as the reconciliation of work and private life, although some scholars criticize that concept and opt for the integration of work and private life (Abendroth \& Dulk, 2011) as an equal division of time between both. Others define the balance as the degree of personal satisfaction when an individual succeeded in achieving harmony in all areas of life. These authors characterize work-life balance as the degree to which a person engages in and is equally satisfied with their work - life roles, consisting of the following three aspects of work-life balance: time balance, participation balance, and satisfaction balance (Oosthuizen et al., 2016). This idea is in tune with the current study.

Various research studies have discussed the effect of organisational, individual, external, and demographic factors on work - life balance (Abendroth \& Dulk, 2011; Poulose \& Sudarsan, 2017). According to scholarly literature, the largest positive effect on WLB is produced by such factors as supervisor assistance in reducing stress at work (Bell et al., 2012; Humayon et al., 2018), transformational leadership (Munir et al. 2012), a healthy work environment (Nordenmark et al., 2012), flexible work practices, and the ability to control work place and time (Hayman, 2010; Emre \& Spiegeleare, 2019), partner support (Abendroth \& Dulk, 2011), and individual efforts to balance out well-being (Zheng et al., 2016).

It should be noted that the reconciliation of work and private life is a complex phenomenon that depends on both an individual's personal life situation and a situation at work (Eurofound, Dublin, 2012). Successful WLB is positively associated with lower turnover, organisational citizenship behaviour, higher work engagement, increased productivity and organisational commitment (Kim, 2014), as well as job satisfaction, life and employee wellbeing (Taşdelen-Karçkay \& Bakalım, 2017). On the other hand, the inability to combine work and family roles, psychological disengagement from work, work overload, inadequate work requirements, lack of a healthy environment at work, etc. has a negative effect on family and satisfaction with well-being (Nordenmark et al., 2012; Kalliath et al., 2017; Skurak et al., 2018), causes anxiety and psychological tension, and stress at work (Taşdelen-Karçkay \& Bakalım, 2017).

Thus, WLB is an important determinant of well-being (Beauregard, 2011; Bentley et al., 2016; Taşdelen-Karçkay \& Bakalım, 2017), and there are both positive and negative relationships between WLB and well-being (Beauregard, 2011; Bentley et al., 2016; Taşdelen-Karçkay \& Bakalım, 2017).

\subsection{Work culture impact on employee well-being and the mediating role of work- life balance}

Some scholars (Santos et al., 2013) analyse the culture that exists in the organization as an important organizational factor in WLB. The employees who perceive the desired culture will be held to stay in the group as the feeling of the culture they desire forms a social bond 
and helps them stick together (Ismail et al., 2018). The existing organisational family-friendly culture promotes tolerance, and the employees who feel the support of employers are not afraid of expressing the issues related to work-life balance (Santos et al., 2013).

This organisational culture could be treated as work culture which is born out of the organisation's strategic intent and values (Padhi, 2017). According to Clark (2001), a lot of organisations change their culture in order to become a work culture that is more "familyfriendly". This approach to work culture as "family-friendly" culture has been used in the present study.

Bailyn (1997) has identified three characteristics of such culture: temporal flexibility, operational flexibility, and supportive supervision.

Temporal flexibility is the opportunity offered to you to have your own point of view as well as the opportunity to adjust your work schedule. The majority of employers argue that flexible planning increases the productivity, not only reduces employee stress and absenteeism, but also increases the individual job autonomy and efficiency (Hoeven \& Zoonen, 2015; Clarke \& Holdsworth, 2017). Mothers working for companies with generous vacation and flexible scheduling policies feel greater job satisfaction and greater well-being (Moen et al., 2016).

Operational flexibility is defined as control over working conditions and includes the autonomy to decide how work should be done without unnecessary monitoring or restrictions (Bailyn, 1997). Self-employed people are more satisfied with their work and more engaged in work processes as long as their work is not related to stress or fatigue (Boxall \& Macky, 2014). Self-sufficiency is said to be an essential element of employee well-being, motivation and engagement (Olesen et al., 2015). Organisations with integrated operational flexibility have more productive and satisfied employees, which gives them the freedom to manage their family affairs and ensure the absence of conflicts between work and family (Rastogi et al., 2016).

Supportive supervision is the direct support of the supervisor to people with family responsibilities (Bailyn, 1997). The well-being of employees depends on positive communication between the person and the manager, mutual support, and honesty. A supervising support reduces stress and role conflict, increases loyalty to the organisation and well-being (Matthews et al., 2014).

Previous researchers have found the relationship that exists between work culture and WLB (Clark, 2001; Santos et al., 2013; Rastogi et al., 2016; Humayon et al., 2018) and work culture and well-being (Beauregard, 2011; Bentley et al., 2016).

It should be noted that the examination of "family-friendly" work culture revealed its effect on work and family (Abendroth \& Dulk, 2011). And this is in tune with the employees' need to balance the significant responsibilities both at work and with family. The findings of numerous studies have shown that the perception of support at home has been associated with a greater job satisfaction (Bentley et al., 2016), an increased organisational commitment and a decreased intention to change jobs (Ahmad \& Omar, 2010; Singh et al., 2018). The team members who perceive the management aiming to support family policy, experience less stress at work and a greater sense of balance in the family (Ni \& Wang, 2015; Caesens et al., 2017; Humayon et al., 2018), as well as the support from line managers is associated 
with satisfaction with work and private life well-being (Beauregard, 2011). A study by Santos et al. (2013) showed a link between work culture and subjective well-being and a study by Clark (2001) confirmed that operational flexibility and supportive supervision had a direct impact on WLB, while the impact of temporal flexibility on balance was indirect.

Based on that evidence it is worth to check if WLB can not only make a direct impact on employee well-being, but also play a mediating role between the family friendly work culture and well-being. The studies of this kind are still scarce. The analysis has shown that WLB has a mediating effect on the relationship between work-family conflict and job and family satisfaction (Pattusamy \& Jacob, 2016). Taşdelen-Karçkay and Bakalım (2017) revealed that WLB was a full mediator between work-family and family-work conflict and life satisfaction. Thus, based on the literature, it can be stated that:

$\mathrm{H}_{1}$ - WLB mediates the relationship between work culture and employee well-being.

As mentioned earlier, there are links between the structural elements of work culture and well-being. Moen (2016) proved a link between temporal flexibility and job satisfaction and greater well-being. Olesen et al. (2015) found that the operational flexibility element predicts employee well-being, motivation, and engagement. And a supervising support reduces stress and role conflict, increases loyalty to the organization and well-being (Matthews et al., 2014). Based on the previous studies, it could be presupposed that if WLB mediates the relationship between work culture and employee well-being, its structural elements also predict similar relationships. According to ter Hoeven and van Zoonen (2015), WLB has a mediating effect on the relationship between temporal flexibility as a work culture dimension and employee well-being. So we assume that:

$\mathrm{H}_{2}$ - WLB mediates the relationship between temporal flexibility and employee wellbeing.

$\mathrm{H}_{3}$ - WLB mediates the relationship between supportive supervision and employee wellbeing.

$\mathrm{H}_{4}$ - WLB mediates the relationship between operational flexibility and employee wellbeing.

Hence, the current study tends to fill the existing knowledge gap in understanding the mediating role of WLB on the relationship between work culture and employee well-being.

\section{Methodology}

The empirical data were collected using a survey method. A questionnaire was prepared using the constructs suggested by academic literature in the English language. Then the rule of double translation was applied to verify their consistency in applying the questionnaire in the Lithuanian language. To conduct mediation analysis, IBM SPSS and special PROCESS macro have been used.

\subsection{Variables measurement}

A conceptual model of the research suggested the application of three variables to verify the relationships between the dimensions explored. All the three variables applied were taken from the verified academic sources. To measure employee well-being, the Short Smith 
Well-being Questionnaire (Short-Swell) was selected (Smith \& Smith, 2017). Ten items measured the level of well-being, some of them reflected the positive aspects of well-being, while some the negative. The examples of questions representing positive features of well-being were statements like "To what extent does your job have positive characteristics" or "Do you think you have a positive personality?" The examples of statements with negatives aspects would be "To what extent does your job have negative characteristics?" or "To what extent do you deal with problems in a passive way?". The scale applied in our research was reduced from the original 1 to 10 version to 1 to 5 for the present research, where 1 meant "Not at all" and 5 "Very much so". The unanimity of scales used in our research was applied to ease the task for respondents to provide considered evaluations of different dimensions of the survey and to make the comparison of those evaluations easer to interpret.

Work culture was measured using Clark's (2001) Work Culture Variables questionnaire consisting of 13 items. All the items were measured on a 5-point Likert scale from "Strongly disagree" to "Strongly agree". The items reflected the following three dimensions of culture: temporal flexibility (5 items), supportive supervision (3 items) and operational flexibility (5 items). The first group included such time pointing items like "I am able to arrive and depart from work when I want" or "It is O.K. with my employer if I work from home". Second group included items like "My supervisor understands my family demands" and "My supervisor acknowledges that I have obligations as a family member". Operational flexibility was measured using such statements like "I can choose what I do at work" and "I have a say in what goes on at work".

The mediating factor was measured using an 8-item Work-Life Balance Scale constructed by Taşdelen-Karçkay and Bakalim (2017). The examples of items would be the statements like "I can make enough time for myself by preserving the balance between my professional life and family life" and "I can deal with the situations that occur due to the conflict between my roles that are specific to my professional and family life". All the statements were evaluated using a 5-point Likert scale ranging from "Strongly disagree" to "Strongly agree".

The control variables included a description of the organisation of the respondent (area of activities, size, and ownership type) and a description of the respondent (gender, age, education, marital status and dependent members in the family).

\subsection{Sample and data collection}

The data for empirical research were collected by means of an online questionnaire hosted on a popular survey site in Lithuania over the period from October through November 2019. The target population included all the employees employed by business or government organisations. Convenience sampling was applied to collect the data. The respondents were approached individually and through their organizations. The e-mails with reference to the site of the survey were send to different organizations asking them to redirect the reference to their employees or were sent directly to some employees asking them to share the reference with co-workers. In total, 402 questionnaires were filled by the respondents.

The respondents came from a wide range of areas of activities and organisations diverse in the type and size of ownership, therefore the structure of local economy was well repre- 
sented. The highest proportion (33.9\%) of subjects were represented by the biggest employers (with more than 250 employees) what in the case of a small country like Lithuania meant quite large organisations; $28 \%$ of the respondents worked in service industries, while $18.2 \%$ of them - in trade, and a comparatively small part of the respondents (9.1\%) were involved in manufacturing businesses. The majority of the respondents were employed in the affiliates of private local (52.5\%) or foreign companies (25.1\%), while $15.5 \%$ of the subjects worked in public sector.

In terms of individual characteristics, the sample was biased toward female respondents (75.2\%) over male respondents (24.8\% respondents) and toward younger respondents over the older. In all, the youngest age range of the respondents aged from 19 to 29 comprised $46.8 \%$ of all the respondents, while the next age range from 30 to 39 covered $31.7 \%$, those aged from 40 to $49-17.1 \%$ and those over 50 - only $4.3 \%$ of respondents. The majority of the respondents held university $(52.5 \%)$ or college $(31.1 \%)$ degrees, while $9.8 \%$ of them finished the secondary education (12 years), $1 \%$ failed to finish the secondary education, and $5.6 \%$ completed vocational education.

The issue of WLB is particularly susceptible to family matters. The majority of the respondents (76\%) lived with partners, $26.2 \%$ of them had under-school aged children, $19.1 \%$ of them were with school-aged children and $15.4 \%$ had to care about other dependents (old parents, incapacitated siblings or relatives and similar).

\subsection{Data analysis}

To test the hypotheses, mediation analysis was applied. Mediation refers to a situation when the relationship between a predictor variable and an outcome variable can be explained by their relationship to a third variable (Field, 2018). Four mediation analyses were carried out with four different but closely related predictors, while outcome variable and mediating variables remained the same. Predictors included work culture variable and its latent variables - temporal flexibility, supportive supervision and operational flexibility, dependent variable - employee well-being, and mediating variable - WLB. Mediating impact was tested through a series of linear models as suggested by Field (2018) and Hayes (2018). The direct and indirect effects of predictors on the outcome variable were calculated using 5000 bootstrap sampling procedure, SPSS special PROCESS macro, which allowed to generate confidence intervals for the effects calculated. The decision rule whether to accept mediation or to reject it, was based on the evaluation of those intervals. The rule states that if confidence interval includes zero value, the mediating effect should be rejected, otherwise it should be accepted (Field, 2018; Hayes, 2018).

\section{Research results}

\subsection{Scales reliability, descriptive statistics and correlations}

All the constructs used in data analysis were checked for scale reliabilities using Cronbach's Alfa test. The test values did not show any problems with the data application for the subsequent analysis. The values fluctuated from 0.70 for Operational flexibility of Work culture 
latent variable (see Table 1) up to 0.91 for Supportive supervision latent variable and WLB scales. Those values were within the range indicated by Field (2018) and suggested good reliability.

Table 1. Reliabilities, means, standard deviations and correlations

\begin{tabular}{|c|l|c|c|c|c|c|c|}
\hline & & 1 & 2 & 3 & 4 & 5 & 6 \\
\hline & Reliability & 0.91 & 0.86 & 0.88 & 0.82 & 0.91 & 0.70 \\
\hline & Mean & 3.51 & 3.45 & 3.15 & 2.78 & 3.25 & 3.45 \\
\hline & Std. deviation & 0.82 & 0.71 & 0.75 & 1.00 & 1.00 & 0.73 \\
\hline 1 & Work-Life Balance & 1 & & & & & \\
\hline 2 & Well-being & 0.58 & 1 & & & & \\
\hline 3 & Work Culture & 0.56 & 0.64 & 1 & & & \\
\hline 4 & Temporal flexibility & 0.44 & 0.47 & 0.89 & 1 & & \\
\hline 5 & Supportive supervision & 0.47 & 0.56 & 0.78 & 0.56 & 1 & \\
\hline 6 & Operational flexibility & 0.49 & 0.59 & 0.80 & 0.51 & 0.49 & 1 \\
\hline
\end{tabular}

Note: Correlation is significant at the 0.01 level (2-tailed).

All the three constructs were measured using a 5-point scale. The evaluations centred around the middle of the scale with some focus toward the upper end, but generally they meant that there was neither much of excitement, nor much of disappointment with the dimensions discussed. WLB $(\mathrm{M}=3.51, \mathrm{SD}=0.82)$ received the most positive evaluations while less satisfaction was caused by Work Culture $(\mathrm{M}=3.15, \mathrm{SD}=0.75)$. The greatest dissatisfaction was caused by Temporal Flexibility $(\mathrm{M}=2.78, \mathrm{SD}=1.00)$, one of the dimensions of work culture. Having in mind the specifics of the sample, we could conclude that educated females living in families with partners and many with children were not satisfied with the flexibility of work schedules they should stick with, what received some reflection in the evaluations. At this point it is worth noting that the standard deviation reaching one point on a 5-point scale in this evaluation was also the highest, what meant that disagreement demonstrated in these evaluations were also the highest. So, on the one hand, the data showed that there were a number of the respondents very frustrated with temporal work flexibility, while on the other hand, there were also those who were satisfied with the time management opportunities provided at their work. Supportive supervision is another problematic dimension of work culture where the respondents expressed less satisfaction $(M=3.25)$ and had higher disagreement levels $(\mathrm{SD}=1.00)$.

The correlation analysis showed the dependences between the variables researched. A strong correlation can be found between work culture variable and its latent variables. Those variables are applied in this research only in separate mediating models, therefore this correlation makes no effect on research findings and can be ignored. The correlations between the models' predictors (work culture, temporal flexibility, supportive supervision, operational flexibility), the mediator (WLB) and the dependent variable (employee well-being) are in the middle range. The strongest correlation exists between the attractiveness of work culture and feeling of well-being $(r=0.64)$. Out of cultural dimensions, operational flexibility correlates 
the most with employee well-being $(r=0.59)$, but the differences are not big $(r=0.56$ for supportive supervision and $r=0.47$ for temporal flexibility). WLB as a mediating variable in the research model has a similar correlation with both well-being $(r=0.58)$ and work culture $(r=0.56)$. This implies that there is some relationship between those three variables, therefore, it has sense to aggregate them in the mediator model. The correlations with cultural dimensions are lower, but still in the middle range and significant, so their inclusion into the model is also possible.

\subsection{Mediator analysis}

Mediating analysis implies a set of regression analysis conducted in a particular order (Field, 2018; Hayes, 2018). Four separate mediator analyses were conducted in this study where Work Culture was taken as a predictor to predict Employee Well-being, while WLB was taken as a mediator. In the next stage, Temporal flexibility, Supportive Supervision and Operational flexibility as the individual components of the Work Culture construct were used as independent predictors to determine the relationship with the Employee well-being, leaving the mediator's role to the Work life balance (WLB).

Table 2. The linear regression effect of work culture and its dimensions on WLB

\begin{tabular}{|c|c|c|c|c|c|c|}
\hline \multirow{2}{*}{ R-sq } & \multirow{2}{*}{ F } & \multicolumn{2}{|c|}{ Constant } & \multicolumn{3}{c|}{ Coefficients } \\
\cline { 3 - 7 } & & value & $\mathrm{t}$ & unst B & $\mathrm{t}$ & $\operatorname{stan} \beta$ \\
\hline \multicolumn{7}{|c|}{ Work culture ->WLB } \\
\hline 0.31 & $178.2^{*}$ & 1.59 & $10.73^{*}$ & 0.61 & $13.35^{*}$ & 0.56 \\
\hline \multicolumn{7}{|c|}{ Temporal flexibility ->WLB } \\
\hline 0.19 & $93.0^{*}$ & 2.52 & $22.94^{*}$ & 0.36 & $9.64^{*}$ & 0.44 \\
\hline \multicolumn{7}{|c|}{ Supportive supervision ->WLB } \\
\hline 0.22 & $110.7^{*}$ & 2.27 & $18.38^{*}$ & 0.38 & $10.52^{*}$ & 0.47 \\
\hline \multicolumn{7}{|c|}{ Operational flexibility ->WLB } \\
\hline 0.24 & $122.6^{*}$ & 1.64 & $9.44^{*}$ & 0.55 & $11.07^{*}$ & 0.49 \\
\hline
\end{tabular}

Note: ${ }^{\star}$ Coefficient is significant at the 0.01 level.

This paper presents all the four mediator analyses in a step-by-step order. The first step in mediation analysis was the linear regression analysis carried out to determine the relationship between the predictor and the mediator. As seen in Table 2, all the four regression analyses showed statistically important relationships between the predictor (work culture and its dimensions) and the mediator (WLB). The strongest relationship was reported by the Work Culture variable. This variable accounted for $31 \%$ of the changes in the work-life variable. Out of the structural parts of the construct, Operational flexibility played the most obvious role in the changes of balance evaluation $\left(\mathrm{R}^{2}=0.24\right)$.

The standardized regression coefficient was also the highest for the whole construct ( $\beta=0.56)$, followed by Operational flexibility $(\beta=0.49)$, Supportive supervision $(\beta=0.47)$ and Temporal flexibility $(\beta=0.44)$. 
The next step in the mediator analysis was the multiple regression analysis where the predictor and the mediator were taken as independent variables to predict the outcome. In our case we analysed how employee well-being could be explained by using work culture/ its dimensions and WLB as independent variables. The results of the analysis are represented in Table 3.

Table 3. The linear regression effect of work culture, its dimensions and WLB on employee well-being

\begin{tabular}{|c|c|c|c|c|c|c|c|c|c|}
\hline \multirow{2}{*}{ R-sq } & \multirow{2}{*}{$\mathrm{F}$} & \multicolumn{2}{|c|}{ Constant } & \multicolumn{3}{|c|}{ Culture coefficients } & \multicolumn{3}{|c|}{ Balance coefficients } \\
\hline & & value & $\mathrm{t}$ & unst B & $\mathrm{t}$ & $\operatorname{stan} \beta$ & unst B & $\mathrm{t}$ & $\operatorname{stan} \beta$ \\
\hline \multicolumn{10}{|c|}{ Work culture + WLB -> Well-being } \\
\hline 0.48 & $183.6^{*}$ & 1.06 & $8.33^{\star}$ & 0.43 & $10.40^{\star}$ & 0.45 & 0.29 & $7.59^{*}$ & 0.33 \\
\hline \multicolumn{10}{|c|}{ Temporal flexibility + WLB ->Well-being } \\
\hline 0.39 & $128.7^{*}$ & 1.49 & $11.74^{*}$ & 0.19 & $5.96^{*}$ & 0.26 & 0.41 & $10.81^{*}$ & 0.47 \\
\hline \multicolumn{10}{|c|}{ Supportive supervision + WLB ->Well-being } \\
\hline 0.44 & $154.2^{*}$ & 1.35 & $10.85^{*}$ & 0.26 & $8.56^{*}$ & 0.37 & 0.35 & $9.55^{*}$ & 0.41 \\
\hline \multicolumn{10}{|c|}{ Operational flexibility + WLB -> Well-being } \\
\hline 0.46 & $166.6^{*}$ & 0.92 & $6.52^{*}$ & 0.39 & $9.46^{*}$ & 0.40 & 0.33 & $9.05^{*}$ & 0.38 \\
\hline
\end{tabular}

Note: ${ }^{*}$ Coefficient is significant at the 0.01 level.

The analysis showed that WLB and Work Culture and its dimensions were good predictors of employee Well-being. $\mathrm{R}$ square reached 0.48 when full Work Culture construct was taken, 0.46 when only Operational flexibility was dealt with, 0.44 - when the effect of Supportive supervision was examined and 0.39 in case of Temporal flexibility. Both the independent variables related to work culture and WLB variables were significant at the level 0.01 which meant that both of them were appropriate predictors for a dependent variable.

Standardized regression coefficients referring to the relations between the mediator WLB and Well-being varied between 0.33 (Work culture) and 0.41 (Temporal flexibility) depending on which work culture dimension was considered. Affected by the second independent variable (mediator) standardized regressions coefficients, referring to the relationship between the predictor - Work culture/ its dimensions and the outcome - employee Well-being were fluctuating between 0.45 (the predictor - Work culture) and 0.26 (the predictor - Temporal flexibility).

The next stage was the calculation of a direct effect of the predictor on the outcome variable. The data of the linear regression analysis carried out between the predictor, in our case, work culture or some of its dimensions, and the outcome variable, that is, employee well-being is presented in Table 4. Obviously, the direct linear regression relationship was strongest with Temporal flexibility as the predictor $\left(\mathrm{R}^{2}=0.46\right)$, slightly less obvious with Work culture as the predictor $\left(R^{2}=0.41\right)$, even less - with Operational flexibility $\left(R^{2}=0.35\right)$ and the least - with Supportive supervision $\left(R^{2}=0.31\right)$. Standardized regression coefficients were the highest for Work culture as the predictor (0.64) and the lowest for Temporal flexibility (0.46).

The last step in the mediation analysis represented the assessment of the mediator effect on the predictor-outcome relationship and drawing the conclusions on the existence of mediation. Table 5 provides the major statistical findings and the conclusions on the hypotheses 
tested. The mediation analysis proved that all the four hypotheses were supported. WLB plays a mediator role in the relationship between Work culture and employee Well-being as well as for Work culture's structural dimensions.

Table 4. The linear regression effect of work culture and its dimensions on employee well-being

\begin{tabular}{|c|c|c|c|c|c|c|}
\hline \multirow{2}{*}{ R-sq } & \multirow{2}{*}{ F } & \multicolumn{2}{|c|}{ Constant } & \multicolumn{3}{c|}{ Coefficients } \\
\cline { 3 - 7 } & & value & $\mathrm{t}$ & unst B & $\mathrm{t}$ & $\operatorname{stan} \beta$ \\
\hline \multicolumn{7}{|c|}{ Work culture ->Well-being } \\
\hline 0.41 & $271.1^{*}$ & 1.52 & $12.68^{*}$ & 0.61 & $16.46^{*}$ & 0.64 \\
\hline \multicolumn{7}{|c|}{ Temporal flexibility -> Well-being } \\
\hline 0.46 & $108.8^{*}$ & 2.52 & $26.70^{*}$ & 0.33 & $10.43^{*}$ & 0.46 \\
\hline \multicolumn{7}{|c|}{ Supportive supervision -> Well-being } \\
\hline 0.31 & $176.9^{*}$ & 2.15 & $21.30^{*}$ & 0.40 & $13.30^{*}$ & 0.56 \\
\hline \multicolumn{7}{|c|}{ Operational flexibility -> Well-being } \\
\hline 0.35 & $208.8^{*}$ & 1.47 & $10.49^{*}$ & 0.57 & $14.45^{*}$ & 0.59 \\
\hline
\end{tabular}

Note: ${ }^{*}$ Coefficient is significant at the 0.01 level.

Overall, on the basis of the mediation analysis, we conclude that there was a significant indirect effect of Work culture on employee Well-being through WLB, B $=0.177,95 \%$ BCa CI $[0.111 ; 0.247]$, with the total effect equal to 0.611 . The mediating effect of WLB was also found in all the three interactions between cultural dimensions and well-being. The moderating effect was the strongest for the operational flexibility impact on well-being $(\mathrm{B}=0.182$, $95 \%$ BCa CI $[0.123 ; 0.251])$, with the total effect of 0.574 . The other two dimensions had a smaller total impact on well-being, 0.333 for temporal flexibility and 0.400 for supportive supervision respectively, but the indirect effect of WLB on the impact was still obvious. The indirect effect $\mathrm{B}=0.147,95 \% \mathrm{BCa}$ CI $[0.100 ; 0.195]$ was for temporal flexibility and $\mathrm{B}=0.136,95 \%$ BCa CI $[0.091 ; 0.186]$ for supportive supervision.

Table 5. Mediation test results

\begin{tabular}{|c|c|c|c|c|c|}
\hline & & Total effect & Direct effect & Indirect effect & $\begin{array}{l}\text { Hypo- } \\
\text { theses }\end{array}$ \\
\hline $\mathrm{H}_{1}$ & $\begin{array}{l}\text { Work culture }-> \\
\text { Balance }->\text { Well-being }\end{array}$ & $\begin{array}{c}0.6110 \\
\text { LLCI }=0.5381 \\
\text { ULCI }=0.6840\end{array}$ & $\begin{array}{c}0.4345 \\
\text { LLCI }=0.3524 \\
\text { ULCI }=0.5167\end{array}$ & $\begin{array}{c}0.1765 \\
\text { BootLLCI }=0.1114 \\
\text { BootULCI }=0.2468\end{array}$ & Confirmed \\
\hline $\mathrm{H}_{2}$ & $\begin{array}{l}\text { Temporal flexibility -> } \\
\text { Balance -> Well-being }\end{array}$ & $\begin{array}{c}0.3332 \\
\text { LLCI }=0.2704 \\
\text { ULCI }=0.3961\end{array}$ & $\begin{array}{c}0.1862 \\
\text { LLCI }=0.1248 \\
\text { ULCI }=0.2476\end{array}$ & $\begin{array}{c}0.1470 \\
\text { BootLLCI }=0.1002 \\
\text { BootULCI }=0.1950\end{array}$ & Confirmed \\
\hline $\mathrm{H}_{3}$ & $\begin{array}{l}\text { Support -> Balance -> } \\
\text { Well-being }\end{array}$ & $\begin{array}{c}0.3953 \\
\text { LLCI }=0.3369 \\
\text { ULCI }=0.4538\end{array}$ & $\begin{aligned} 0.2597 \\
\text { LLCI }=0.2000 \\
\text { ULCI }=0.3194\end{aligned}$ & $\begin{array}{c}0.1356 \\
\text { BootLLCI }=0.0910 \\
\text { BootULCI }=0.1858\end{array}$ & Confirmed \\
\hline $\mathrm{H}_{4}$ & $\begin{array}{l}\text { Operational flexibility } \\
\text {-> Balance -> Well- } \\
\text { being }\end{array}$ & $\begin{array}{c}0.5737 \\
\text { LLCI }=0.4956 \\
\text { ULCI }=0.6517\end{array}$ & $\begin{array}{c}0.3916 \\
\text { LLCI }=0.3102 \\
\text { ULCI }=0.4730\end{array}$ & $\begin{array}{c}0.1821 \\
\text { BootLLCI }=0.1225 \\
\text { BootULCI }=0.2508\end{array}$ & Confirmed \\
\hline
\end{tabular}


So, all the hypotheses were supported, no single $95 \%$ confidence level interval had crossed the zero value. The mediation effect was present in every interaction under analysis. The WLB mediation effect was strongest for Operational flexibility and the general Work culture impact on employee Well-being. However, it is important to point out that the direct effect of work culture on employee well-being was much greater than the indirect one in all the interactions examined.

\section{Discussion}

As the literature review has shown, most scholars have examined either the relationship between work culture and well-being only (Santos et al., 2013) or the relationship of structural work culture elements with well-being (Moen et al., 2016; Olesen et al., 2015; Matthews et al., 2014), i.e. have determined whether the relationship is direct. We have extended the scientific discussion emphasizing that the relationship can also be indirect through work-life balance. The present research has proven the role of WLB as a mediator in the relationship between work culture and employee well-being in organisational settings. This is partly in tune with previous studies which disclosed that WLB could be treated as a mediator for work-family conflict/family-work conflict and life satisfaction (Taşdelen-Karçkay \& Bakalim, 2017) and for flexible work designs and well-being (Hoeven \& Zoonen, 2015).

The results of our study also revealed that a direct effect of work culture on well-being was much stronger than the one mediated by an indirect effect of WLB. This can be explained by the fact that a flexible family friendly work culture is the most important prerequisite to reach higher levels of employee well-being. The research showed that a flexibility in schedules and a possibility to find the most appropriate location for carrying out the task had some impact on employee sense of well-being, but the content of tasks seemed to be more important. A possibility to plan a job, to have the right of a voice in work discussions seemed to be the factors of great importance for employees who provided judgements on how well they felt at workplaces. Self-direction at work, probably, affected the most fundamental self-determination needs of a person (Deci \& Ryan, 2008), therefore this component was so significant. Leadership and supervision sensitive to employee family responsibilities also played an essential role in defining the level of well-being by an employee.

The current study revealed the mediating effect of WLB on well-being for work culture dimensions. Our research findings supported the conclusion made by ter Hoeven and van Zoonen (2015) that the relationship of temporal flexibility with well-being was mediated by WLB, nevertheless we should keep in mind that different scales were used in both studies, so the results cannot be seen as the duplication of findings. In addition, this study has supplemented the scientific discussion that supportive supervision and well-being and operational flexibility and well-being are mediated by WLB. We believe this is an important result of our study. However, temporal flexibility proved to be the least important factor affecting wellbeing, while operational flexibility was the most important. That finding more or less confirmed the conclusion made by Clark (2001) that flexibility of the work itself was associated with the increased work satisfaction and family well-being, while flexibility of work time was not associated with any work or personal outcome. Nevertheless, it is important to take into 
account the fact that our study measured general employee well-being, while Clark's study was focused on family well-being.

In general, our study postulates that flexible, family-friendly work culture leads to an increased employee well-being. This relationship is partly mediated by WLB. However, it is important to keep in mind that if, in general, work culture has a positive effect on well-being (Santos et al., 2013) and WLB, under some circumstances this effect can either disappear or can even take the opposing direction. Ter Hoeven and van Zoonen (2015) found that flexible work design was negatively associated with employee well-being through the increased interruptions. Further research could focus on revealing the circumstances in which the effect of interruption could occur. The possible variables to be explored could be an employee workload or a lack of career competencies. Investing efforts into poorly selected options could also cause negative effects on both well-being and WLB. Work competencies might be taken as a mediator between job resources measured as cultural variables and employee well-being (Akkermans et al., 2013).

\section{Conclusions}

It has been noticed that the understanding of the importance of employee well-being, WLB and work culture in the organisational environment has been increasingly emphasised in different studies. Though the analysis of the literature suggests that there are direct and indirect links between work-culture, well-being and WLB, there is still a lack of studies concerning the relationship between employee well-being and work culture in the context of the mediating effect of WLB on it.

Our study yields an important conclusion that WLB has a mediating effect on the relationship between work culture and employee well-being. At the same time work culture has both a significant direct impact on well-being and affects WLB. However, this direct effect of work culture on well-being is much stronger than the one mediated by an indirect effect of WLB. Our research has also found that temporal flexibility, supportive supervision and operational flexibility as work culture dimensions have a strong direct impact on well-being and affect WLB. However, temporal flexibility has proven to be the least important factor affecting well-being, while operational flexibility has turned to be the most important.

The results of our study suggest that companies should take actions to find better ways how to help employees in reaching higher levels of WLB which are likely to lead to better employee well-being so that their performance is improved. Nevertheless, this approach should be taken with caution. Therefore, the companies' actions will be wasted if the employees do not develop their own approach to increase their well-being by utilizing the opportunities provided by their companies. These conclusions are very important for practitioners who seek to improve their organisation's performance by enhancing the well-being of their employees.

These findings should be considered having in mind some limitations of the present research. First of all, the sample included a disproportionally large part of young and middleaged female respondents with university and comparable education with a great interest in career development. Their motivation is likely be different from other groups of employees, 
therefore further research with different samples of respondents could provide a better insight into the importance of these differences. It should also be taken into account that all the measurements are built on self-reported data and represent the perceptions of the respondents. Additional research using more objective measures might disclose a different nature of the relationships between the dimensions analysed in this study.

\section{Author contributions}

AS has developed the concept of the study, coordinated the research process, contributed to developing every part of the article. VT participated in developing the empirical research strategy, conducted the data analysis and participated in generalizing the research findings. DD has created theoretical foundations of the research concept, contributed to developing other parts of the article. ŽG contributed to the improvement of the data analysis and the interpretation of findings. LR participated in developing the concept of the study, prepared research tools and administrated the survey process, contributed to improvement of the paper.

\section{Disclosure statement}

The authors declare no competing financial, professional, or personal interests from other parties.

\section{References}

Abendroth, A. K., \& Den Dulk, L. (2011). Support for the work-life balance in Europe: The impact of state, workplace and family support on work-life balance satisfaction. Work, Employment and Society, 25(2), 234-256. https://doi.org/10.1177\%2F0950017011398892

Ahmad, A., \& Omar, Z. (2010). Perceived family-supportive work culture, affective commitment and turnover intention of employees. Journal of American Science, 6(12), 839-846.

Akkermans, J., Schaufeli, W. B., Brenninkmeijer, V., \& Blonk, R. W. B. (2013) The role of career competencies in the job demands-resources model. Journal of Vocational Behavior, 83(3), 356-366. https://doi.org/10.1016/j.jvb.2013.06.011

Bailyn, L. (1997). The impact of corporate culture on work-family integration. In S. Parasuraman \& J. H. Greenhaus (Eds.), Integrating work and family: Challenges and choices for a changing world (pp. 209-219). Quorum Books.

Beauregard, T. A. (2011). Direct and indirect links between organizational work-home culture and employee well-being. British Journal of Management, 22(2), 218-237. https://doi.org/10.1111/j.1467-8551.2010.00723.x

Bell, S. A., Rajendran D., \& Theiler, S. (2012). Job stress, wellbeing, work-life balance and work-life conflict among Australian academics. Electronic Journal of Applied Psychology, 8(1), 25-37. https://doi.org/10.7790/ejap.v8i1.320

Bentley, T. A., Teo, S. T. T., McLeod, L., Tan, F., Bosua, R., \& Gloet, M. (2016). The role of organisational support in teleworker wellbeing: A socio-technical systems approach. Applied Ergonomics, 52, 207-215. https://doi.org/10.1016/j.apergo.2015.07.019

Boxall, P., \& Macky, K. (2014). High-involvement work processes, work intensification and employee wellbeing. Work, Employment and Society, 28(6), 963-984. https://doi.org/10.1177/0950017013512714 
Caesens, G., Stinglhamber, F., Demoulin, S., \& De Wilde, M. (2017). Perceived organizational support and employees' well-being: The mediating role of organizational dehumanization. European Journal of Work and Organizational Psychology, 26(4), 527-540. https://doi.org/10.1080/1359432X.2017.1319817

Carnevale, J., \& Hatak, I. (2020). Employee adjustment and well-being in the era of COVID-19: Implications for human resource management. Journal of Business Research, 116, 183-187. https://doi.org/10.1016/j.jbusres.2020.05.037

Chawla, N., MacGowan, R. L., Gabriel, A. S., \& Podsakoff, N. P. (2020). Unplugging or staying connected? Examining the nature, antecedents, and consequences of profiles of daily recovery experiences. Journal of Applied Psychology, 105(1), 19-39. https://doi.org/10.1037/apl0000423

Clark, S. C. (2001). Work cultures and work/family balance. Journal of Vocational Behavior, 58(3), 348-365. https://doi.org/10.1006/jvbe.2000.1759

Clarke, S., \& Holdsworth, L. (2017). Flexibility in the workplace: Implications of flexible work arrangements for individuals, teams and organizations. Alliance Manchester Business School. University of Manchester, Manchester, M13 9SS. https://www.acas.org.uk/flexibility-in-the-workplace

Cooper, M. P. (2008). Wellness can be a powerful business management strategy, but it takes intelligent planning and execution. Employee Benefit Plan Review, 63(5), 10-11.

Deci, E. L., \& Ryan, R. M. (2008). Facilitating optimal motivation and psychological well-being across life's domains. Canadian Psychology/Psychologie canadienne, 49(1), 14-23. https://doi.org/10.1037/0708-5591.49.3.262

Diener, E., Suh, E. M., Lucas, R. E., \& Smith, H. L. (1999). Subjective well-being: Three decades of progress. Psychological Bulletin, 125(2), 276-302. https://doi.org/10.1037/0033-2909.125.2.276

Dodge, R., Daly, A. P., Huyton, J., \& Sanders, L. D. (2012). The challenge of defining wellbeing. International Journal of Wellbeing, 2(3), 222-235. https://doi.org/10.5502/ijw.v2i3.4

Emre, O., \& De Spiegeleare, S. (2019). The role of work-life balance and autonomy in the relationship between commuting, employee commitment and well-being. The International Journal of Human Resource Management, 1-25. https://doi.org/10.1080/09585192.2019.1583270

Evans, A., Carney, J., \& Wilkinson, M. (2013). Work-life balance for men: Counseling implications. Journal of Counselling \& Development, 91(4), 436-441. https://doi.org/10.1002/j.1556-6676.2013.00115.x

Eurofound. (2012). Working time and WLB in a life course perspective. Eurofound, Dublin. https://www.eurofound.europa.eu/sites/default/files/ef_publication/field_ef_document/ef1273en

Field, A. P. (2018). Discovering statistics using IBM SPSS statistics (5 ${ }^{\text {th }}$ ed.). SAGE Publications. https://www.amazon.com/Discovering-Statistics-Using-IBM-SPSS/dp/1526436566

George, G., Howard-Grenville, J., Joshi, A., \& Tihanyi, L. (2016). understanding and tackling societal grand challenges through management research. Academy of Management Journal, 59(6), 18801895. https://doi.org/10.5465/amj.2016.4007

Goodman, F., Disabato, D., Kashdan, T. B., \& Kauffman, S. B. (2018). Measuring well-being: A comparison of subjective well-being and PERMA. The Journal of Positive Psychology, 13(4), 321-332. https://doi.org/10.1080/17439760.2017.1388434

Grisslich, P., Proske, A., \& Körndle, H. (2012). Beyond work and life - what role does time for oneself play in work-life-balance? ZeitschriftfürGesundheitspsychologie, 20(4), 166-177. https://doi.or.10.1026/0943-8149/a000076

Guest, D. E. (2017). Human resource management and employee well-being: Towards a new analytic framework. Human Resource Management Journal, 27(1), 22-38. https://doi.org/10.1111/1748-8583.12139

Hayes, A. F. (2018). Introduction to mediation, moderation, and conditional process analysis: A regression-based approach ( $2^{\text {nd }}$ ed.). In Methodology in the Social Sciences series. Guilford Press. https://www.afhayes.com/introduction-to-mediation-moderation-and-conditional-process-analysis.html 
ter Hoeven, C. L., \& van Zoonen, W. (2015). Flexible work designs and employee well-being: Examining the effects of resources and demands. New Technology, Work and Employment, 30(3), 237-255. https://doi.org/10.1111/ntwe.12052

Hayman, J. (2010). Flexible work schedules and employee well-being. New Zealand Journal of Employment Relations, 35(2), 76-87. http://www.nzjournal.org/NZJER35(2).pdf

Henrich, G., \& Herschbach, P. (2000). Questions on Life Satisfaction (FLZM): A short questionnaire for assessing subjective quality of life. European Journal of Psychological Assessment, 16(3), 150-159. https://doi.org/10.1027//1015-5759.16.3.150

He, H., \& Harris L. 2020. The impact of Covid-19 pandemic on corporate social responsibility and marketing philosophy. Journal of Business Research, 116, 176-182.

https://doi.org/10.1016/j.jbusres.2020.05.030

Humayon, A. A., Raza, S., Kaleem, N., Murtaza, G., Hussain, M. S., \& Abbas, Z. (2018). Impact of supervision, working condition and university policy on work-life balance of university employees. European Online Journal of Natural and Social Sciences, 7(1), 193-201. https://european-science.com/eojnss/article/view/5253

Ismail, M., Baki, N. U., \& Omar, Z. (2018). The influence of organizational culture and organizational justice on group cohesion as perceived by merger and acquisition employees. Organizations \& Markets in Emerging Economies, 9(2), 233-250. https://doi.org/10.15388/omee.2018.10.00012

Jain, A., Giga, S., \& Cooper, C. (2013). Stress, health and well-being: the mediating role of employee and organizational commitment. International Journal of Environmental Research and Public Health, 10(10), 4907-4924. https://doi.org/10.3390/ijerph10104907

Kalliath, P., Kalliath, T., \& Chan, C. (2017). Work-family conflict, family satisfaction and employee well-being: A comparative study of Australian and Indian social workers. Human Resource Management Journal, 27(3), 366-381. https://doi.org/10.1111/1748-8583.12143

Kim, H. K. (2014). Work-life balance and employees' performance: The mediating role of affective commitment. Global Business and Management Research, 6(1), 37-51. https://www.semanticscholar. org/paper/Work-Life-Balance-and-Employees\%27-Performance\%3A-The-Kim/b2a0018b12b37416 dd8418ef1342bbb34dde02a0

Matthews, R. A., Mills, M. J., Trout, R. C., \& English, L. (2014). Family-supportive supervisor behaviors, work engagement, and subjective well-being: A contextually dependent mediated process. Journal of occupational health psychology, 19(2), 168-181. https://doi.org/10.1037/a0036012

McCarthy, G., Almeida, S., \& Ahrens, J. (2011). Understanding employee well-being practices in Australian organizations. International Journal of Health, Wellness \& Society, 1(1), 181-198. https://doi.org/10.18848/2156-8960/CGP/v01i01/41076

Meyer, J. P., \& Maltin, E. R. (2010). Employee commitment and well-being: A critical review, theoretical framework and research agenda. Journal of Vocational Behavior, 77(2), 323-337. https://doi.org/10.1016/j.jvb.2010.04.007

Mishra, S., \& Kapoor, S. (2017). Non monetary employee welfare activities (strategic move towards changing dynamics of organisation). In Proceedings of International Conference on Strategies in Volatile and Uncertain Environment for Emerging Markets (pp. 179-189).

Moen, P., Kelly, E. L., Fan, W., Lee, S. R., Almeida, D., Kossek, E. E., \& Buxton, O. M. (2016). Does a flexibility/support organizational initiative improve high-tech employees' well-being? Evidence from the work, family, and health network. American Sociological Review, 81(1), 134-164. https://doi.org/10.1177/0003122415622391

Munir, F., Nielsen, K., Garde, A. H., Albertsen, K., \& Carneiro, I. G. (2012). Mediating the effects of work-life conflict between transformational leadership and health-care workers' job satisfaction and psychological wellbeing. Journal of Nursing Management, 20(4), 512-521.

https://doi.org/10.1111/j.1365-2834.2011.01308.x 
Nierenberg, B., Alexakis, G., Preziosi, R. C., \& O’Neill, C. (2017). Workplace happiness: An empirical study on well-being and its relationship with organizational culture, leadership, and job satisfaction. International Leadership Journal, 9(3), 2-23. https://nsuworks.nova.edu/cps_facarticles/1548/

Ni, C., \& Wang, Y. (2015). The impact of perceived organizational support and core self-evaluation on employee's psychological well-being. Journal of Human Resource and Sustainability Studies, 3(2), 73-81. https://doi.org/10.4236/jhrss.2015.32011

Nordenmark, M., Vinberg, S., \& Strandh, M. (2012). Job control and demands, work-life balance and wellbeing among self-employed men and women in Europe. Vulnerable Groups \& Inclusion, 3(1), 18896. https://doi.org/10.3402/vgi.v3i0.18896

Ollier-Malaterre, A., \& Foucreault, A. (2017). Cross-national work-life research: Cultural and structural impacts for individuals and organizations. Journal of Management, 43(1), 111-136. https://doi.org/10.1177/0149206316655873

Olesen, M. H., Thomsen, D. K., \& O’Toole, M. S. (2015). Subjective well-being: Above neuroticism and extraversion, autonomy motivation matters. Personality and Individual Differences, 77, 45-49. https://doi.org/10.1016/j.paid.2014.12.033

Oosthuizen, R. M., Coetzee, M., \& Munro, Z. (2016). Work-life balance, job satisfaction and turnover intention amongst information technology employees. Southern African Business Review, 20(1), 446-467. https://doi.org/10.25159/1998-8125/6059

Orsila, R., Luukkaala, T., Manka, M. L., \& Nygard, C. H. (2011). A new approach to measuring workrelated well-being. International Journal of Occupational Safety and Ergonomics, 17(4), 341-359. https://doi.org/10.1080/10803548.2011.11076900

Padhi, P. (2017). Organisational culture and employee performance. International Journal of Research in IT and Management, 7(5), 77-81. http://euroasiapub.org/wp-content/uploads/2017/06/10IMMay-4884.pdf

Parker, P. D., Martin, A. J., Colmar, S., \& Liem, G. A. (2012). Teachers' workplace well-being: Exploring a process model of goal orientation, coping behaviour, engagement, and burnout. Teaching and Teacher Education, 28(4), 503-513. https://doi.org/10.1016/j.tate.2012.01.001

Pattusamy, M., \& Jacob, J. (2016). Testing the mediation of work-family balance in the relationship between work-family conflict and job and family satisfaction. South African Journal of Psychology, 46(2), 218-231. https://doi.org/10.1177\%2F0081246315608527

Poulose, S., \& Sudarsan, N. (2017). Assessing the influence of work-life balance dimensions among nurses in the healthcare sector. Journal of Management Development, 36(3), 427-437. https://doi.org/10.1108/JMD-12-2015-0188

Qi, D., \& Wu, Y. (2018). Does welfare stigma exist in China? Policy evaluation of the Minimum Living Security System on recipients' psychological health and wellbeing. Social Science \& Medicine, 205, 26-36. https://doi.org/10.1016/j.socscimed.2018.03.041

Rastogi, M., Rangnekar, S., \& Rastogi, R. (2016). Flexibility as a predictor of work-family enrichment. Global Journal of Flexible Systems Management, 17(1), 5-14. https://doi.org/10.1007/s40171-015-0108-y

Robertson, I. T., \& Cooper, C. L. (2010). Full engagement: The integration of employee engagement and psychological well-being. Leadership \& Organization Development Journal, 31(4), 324-336. https://doi.org/10.1108/01437731011043348

Ryff, C. D., \& Keyes, C. L. M. (1995). The structure of psychological well-being revisited. Journal of Personality and Social Psychology, 69(4), 719-727. https://doi.org/10.1037/0022-3514.69.4.719

Sakka, G., \& Ahammad, M. F. (2020). Unpacking the relationship between employee brand ambassadorship and employee social media usage through employee wellbeing in workplace: A theoretical contribution. Journal of Business Research, 119, 354-363. https://doi.org/10.1016/j.jbusres.2020.03.038 
Santos, J., Gonçalves, G., \& Gomes, A. (2013). Organizational culture and subjective and work wellbeing. The case of employees of Portuguese universities. Journal of Spatial and Organizational Dynamics, 1(3), 153-161. https://ideas.repec.org/a/ris/jspord/0009.html

Sheikh, M. A., Ashiq, A., Mehar, M. R., Hasan, A., \& Khalid, M. (2018). Impact of work and home demands on work life balance: Mediating role of work family conflicts. Pyrex Journal of Business and Finance Management Research, 4(5), 48-57. https://www.researchgate.net/publication/327689374_ Impact_of_Work_and_Home_Demands_on_Work_Life_Balance_Mediating_Role_of_Work_Family_Conflicts

Singh, R., Zhang, Y., Wan, M., \& Fouad, N. A. (2018). Why do women engineers leave the engineering profession? The roles of work-family conflict, occupational commitment, and perceived organizational support. Human Resource Management, 57(4), 901-914. https://doi.org/10.1002/hrm.21900

Skurak, H., Malinen, S., Näswall, K., \& Kuntz, J. C. (2018). Employee wellbeing: The role of psychological detachment on the relationship between engagement and work-life conflict. Economic and Industrial Democracy, 42(1), 116-141. https://doi.org/10.1177/0143831X17750473

Smith, A., \& Smith, H. (2017). A short questionnaire to measure wellbeing at work (Short-SWELL) and to examine the interaction between the employee and organisation. In Contemporary Ergonomics and Human Factors 2017 (pp. 200-205). Chartered Institute of Ergonomics and Human Factors, Leicester. http://orca.cf.ac.uk/101213/

Taşdelen-Karçkay, A., \& Bakalım, O. (2017). The mediating effect of work-life balance on the relationship between work-family conflict and life satisfaction. Australian Journal of Career Development, 26(1), 3-13. https://doi.org/10.1177\%2F1038416216682954

Viot, C., \& Benraiss-Noailles, L. (2019). The link between benevolence and well-being in the context of human-resource marketing. Journal of Business Ethics, 159(3), 883-896. https://doi.org/10.1007/s10551-018-3834-1

Zheng, C., Kashi, K., Fan, D., Molineux, J., \& Ee, M. S. (2016). Impact of individual coping strategies and organisational work-life balance programmes on Australian employee well-being. The International Journal of Human Resource Management, 27(5), 501-526. https://doi.org/10.1080/09585192.2015.1020447

Zheng, X., Zhu, W., Zhao, H., \& Zhang, C. (2015). Employee well-being in organizations: Theoretical model, scale development, and cross-cultural validation. Journal of Organizational Behavior, 36(5), 621-644. https://doi.org/10.1002/job.1990 